\title{
Knowledge Attitude and Practice of Geriatric Patients Towards Predictors of Healthy Living at a Tertiary Health Institution in Abuja Nigeria
}

\author{
Christie Omolola Adams ${ }^{1}$, Ebenezer Obi Daniel ${ }^{2, ~}{ }^{*}$, Gabriel Omoniyi Ayeni ${ }^{2}$, Baamlong Nicholas ${ }^{1}$, \\ Ripiye Nanna Rebecca ${ }^{1}$
}

${ }^{1}$ Department of Family Medicine, University of Abuja Teaching Hospital, Abuja, Nigeria

${ }^{2}$ Department of Public Health, School of Public Health, Texila American University, Georgetown, Guyana

\author{
Email address: \\ dannypressy@yahoo.com (E. O. Daniel) \\ *Corresponding author
}

\section{To cite this article:}

Christie Omolola Adams, Ebenezer Obi Daniel, Gabriel Omoniyi Ayeni, Baamlong Nicholas, Ripiye Nanna Rebecca. Knowledge Attitude and Practice of Geriatric Patients Towards Predictors of Healthy Living at a Tertiary Health Institution in Abuja Nigeria. Central African Journal of Public Health. Vol. 5, No. 4, 2019, pp. 165-171. doi: 10.11648/j.cajph.20190504.15

Received: June 5, 2019; Accepted: July 4, 2019; Published: July 15, 2019

\begin{abstract}
The main objective of this study is to determine the knowledge, attitude and practices (KAP) of the geriatrics towards the predictor of healthy living in a tertiary hospital in Abuja, Nigeria. The study was carried out at the University of Abuja Teaching Hospital (UATH), Abuja - Nigeria. A descriptive cross sectional survey of the geriatric patients attending Clinic at the University of Abuja Teaching Hospital, Gwagwalada - Abuja - Nigeria, was carried out. Data was obtained through the use of structured, self-administered questionnaire. Summated scores were used to grade respondents' knowledge attitudes and practices towards predictors of healthy living. Data analysis was done using the Statistical package for Social Science (SPSS) version 21. Data were presented using descriptive statistics of tables, frequencies, percentages, and pie charts. Inferential statistics of Chi-square was used to test for associations between socio-demographic variables and the knowledge, attitude and practice of geriatric patients towards predictors of healthy living. Out of 319 respondents, 50.5\% have good knowledge while $49.5 \%$ have poor knowledge towards predictors of healthy living. It was also revealed in the study that a greater proportion of the respondents $(52 \%)$ have poor attitude towards predictors of healthy living while less than half $(48 \%)$ have good attitude. It was further discovered that $58.6 \%$ of the respondents have poor practice, while only $41.4 \%$ have good practice towards predictors of healthy living. Inferentially, Chi-square revealed that there was statistical significant association between marital status and knowledge of the respondents towards predictors of healthy living $(\mathrm{P}<0.05)$. Furthermore, the level of education and religion of the respondents was found to have statistical significant association with their attitude towards predictors of healthy living $(\mathrm{P}<0.05)$ and there was statistical significant association between the educational level and religion of the geriatric patients and their practice towards predictor of healthy living $(\mathrm{P}<0.05)$. There is a need for action from all concerned stakeholders to improve the KAP of the geriatric population towards predictors of healthy living. Suggested recommendations among others are; that government should enact enabling laws that will promote geriatrics' healthy living, improve the community awareness on the predictors of healthy living among geriatrics through health promotions and provide qualitative education and training/retraining courses for health workers to improve their knowledge on geriatrics health and to effectively take up their roles in educating the target population.
\end{abstract}

Keywords: Geriatrics, Predictors of Healthy Living, University of Abuja Teaching Hospital

\section{Introduction}

Getting older is a process that everything that has life must go through. However, there are some factors that can play a role in making aging process interesting. The sustainable development goal highlighted the key factor that can contribute to aging well. Some of the factors are as follows: 
diet and lifestyle play a huge role in how we look and feel. Aging is not about getting sick or inability to carry out the activity of daily living (ADL) unassisted; aging can be healthfully and feel as optimal as possible.

The evaluation of geriatric patients' knowledge, attitude and practice (KAP) predictor towards health interventions was focused on the KAP model i.e. understanding of individual differences among geriatric to fathom their understanding.

Although various researchers have proposed different existing theoretical models of the knowledge-attitudepractice relationship, the most frequently applied ordering of the KAP variables is the cognitive model [1].
This theoretical model "argues that individuals first learn about a practice, and then develop a positive attitude toward it, and after passing through these stages, engage in the behavior" [1].

Below is the illustration of KAP hypothesis paths

H1: Knowledge predicting positive attitudes towards healthy/successful aging.

$\mathrm{H} 2$ : Attitudes predicting positive behavior towards healthy/successful aging

H3: Practice of successful aging is being predicted by the positive behavior

H4: Self efficacy is a prerequisite of behavior

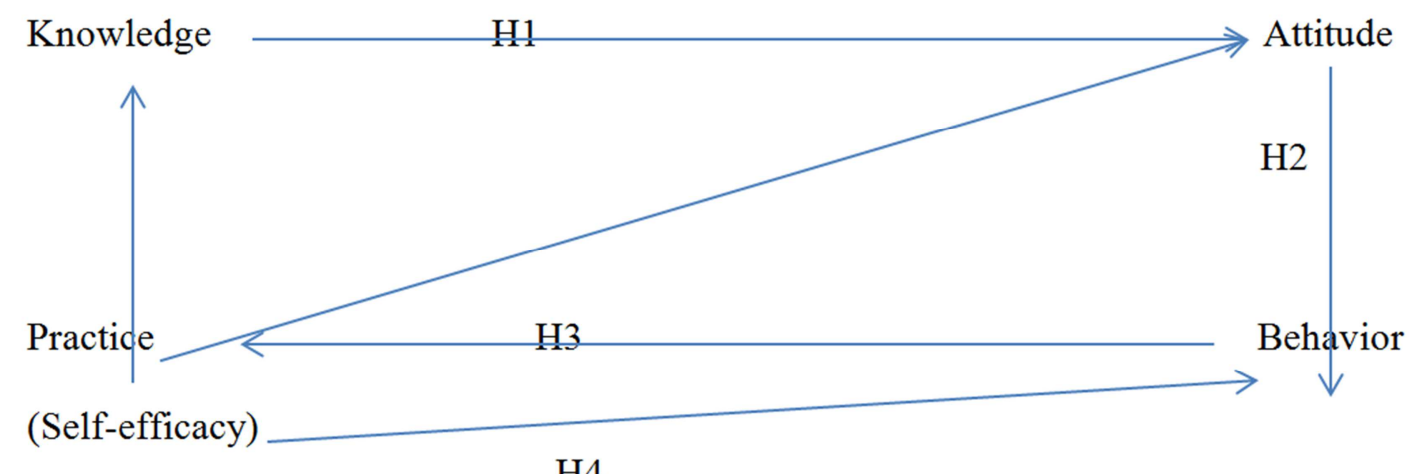

Figure 1. Knowledge attitude and practice hypothesis path.

Other recent models of behavioral change have incorporated additional key constructs. The most common addition is Bandura's [2] concept of self-efficacy that has been integrated into Ajzen's [3] Theory of Planned Behavior; Rosenstock, Strecher, and Becker's (1988) Health Belief Model; and Fishbein and Cappella's (2006) Integrated Model of Behavioral Prediction. Self-efficacy refers to an individual's assessment of his or her own ability to perform a particular behavior [2]. Bandura argues that self-efficacy is one of the most important prerequisites of behavior. Prior research indicates that individuals with low self-efficacy who are not confident in their ability to perform a particular behavior tend to either not try to perform the behavior in question, or to give up easily when facing adversity [2].

Hence, this study was aimed at unraveling the degree at which the geriatric patients at UATH are in tandem with the desired knowledge, attitude and practice towards predictors of healthy living, knowing full well the importance of concentrating on the good health of this negligible population.

\section{Method}

A descriptive cross sectional study of geriatric patients attending clinic at the University of Abuja Teaching Hospital (UATH) from June 2017 to May 2019. The participants' selection into the study was done using simple random sampling. Ethical approval was obtained from the University of Abuja Teaching Hospital, Health Research Ethical Committee (HREC). Data was obtained through the use of structured, self-administered questionnaire, which was reviewed by three public health researchers and their inputs were incorporated in the final version. The questionnaire was subjected to a pilot study with twenty participants to test the degree of the participants' understanding and response to the instrument.

The data was analyzed using Statistical package for Social Sciences (SPSS version 21), and results were presented by percentages, tables and charts. Chi-square was used to test for association between the socio-demographic variables and geriatrics' Knowledge, Attitude and Practice. Single blinding approach was used to ensure that, the researcher did not influence the participants' responses and unaware of the participants' reactions to KAP questions. This was done to minimize researcher's bias. Hence, two trained research assistants were trained and recruited to administer the questionnaire to the participants and collate the data for analysis.

In order to produce a more objective assessment of knowledge attitude and practice of the geriatrics patients, scoring system method was used. Correct or "yes" items was scored " 1 " and incorrect or 'No' was scored ' 0 '. The score of each of the respondent on knowledge, attitude and practice was obtained by adding up the score for correct answers given. A score of $80 \%$ indicated good knowledge/good attitude/ good practice.

\section{Result}

Three hundred and twenty (320) questionnaires were 
administered to the geriatric patients and 319 questionnaires were fully completed and returned. This gave $99.7 \%$ response rate. The recruited sample size is well consistent with the estimated sample size of the study, which was 317 , with $10 \%$ non-response rate inclusive. Out of $100 \%$ (319) respondents, $50.1 \%$ have good knowledge while $49.5 \%$ have poor knowledge towards predictors of healthy living (Figure $1)$. A greater proportion of the respondents $(52 \%)$ have poor attitude towards predictors of healthy living while less than half (48\%) have good attitude (Fig 2), and in the same vein, a considerably high proportion of the respondents (58.6\%) have poor practice towards predictors of healthy living while less than half $(41.4 \%)$ have good practice.

Inferentially, there was statistical significance association between marital status and knowledge of the respondents $(\mathrm{P}<0.05)$ which implies that marital status may responsible for the varying degrees of the knowledge of the respondents towards the predictors of healthy living (Table 2). Age, level of education, employment status and religion were not found to have statically significant association with the knowledge of the respondents towards predictors of healthy living $(\mathrm{P}>0.05)$. Also, level of education and religion were found to have statistically significant association with the attitude of the respondents towards predictors of healthy living $(\mathrm{P}<0.05)$. This implies that level of education and religion may be responsible for the varying degrees of the attitude of the respondents towards the predictors of healthy living (Table 3). Age, Marital status, and employment status were not found to have statistically significant association with the attitude of the respondents towards predictors of healthy living $(\mathrm{P}>0.05)$. Furthermore, the level of education and religion have statistically significant association with the practice of the respondents towards predictors of healthy living $(\mathrm{P}<0.05)$. This suggests that level of education and religion may be responsible for the varying degrees of the practice of the respondents towards the predictors of healthy living (Table 4). Age, Marital status, and employment status were not found to have statically significant association with the practice of the respondents towards predictors of healthy living $(\mathrm{P}>0.05)$.

Table 1. Socio-demographic characteristic of the respondents $(n=319)$.

\begin{tabular}{lll}
\hline VARIABLE & FREQUENCY & PERCENTAGE \\
\hline SEX & & \\
Male & 198 & 62.1 \\
Female & 121 & 37.9 \\
Total & 319 & 100 \\
AGE & & \\
$60-65$ & 75 & 23.5 \\
$66-70$ & 94 & 29.5 \\
$71-75$ & 101 & 31.7 \\
$76-80$ & 26 & 8.2 \\
$81-85$ & 11 & 3.4 \\
$86-90$ & 12 & 3.8 \\
Total & 319 & 100.0 \\
MARITAL STATUS & & \\
Single & 40 & 12.5 \\
\hline
\end{tabular}

\begin{tabular}{lll}
\hline VARIABLE & FREQUENCY & PERCENTAGE \\
\hline Married & 169 & 53.0 \\
Divorce & 49 & 15.4 \\
Widow & 42 & 13.2 \\
Widower & 19 & 6.0 \\
Total & 319 & 100.0 \\
EDUCATIONAL QUALIFICATION & \\
None & 50 & 15.9 \\
Primary & 121 & 38.4 \\
Secondary & 78 & 24.8 \\
Tertiary & 65 & 20.6 \\
Post Graduate & 5 & 0.3 \\
Total & 319 & 100.0 \\
EMPLOYMENT STATUS & & \\
Housewife & 65 & 21.0 \\
Self Employed & 136 & 43.9 \\
Government Employee & 60 & 19.4 \\
Private Employee & 40 & 9.9 \\
Others & 18 & 5.8 \\
Total & 319 & 100.0 \\
RELIGION & & \\
Christianity & 124 & 39.6 \\
Islam & 171 & 54.6 \\
Others & 24 & 5.8 \\
Total & 319 & 100.0 \\
\hline
\end{tabular}

From table 1 above, it can be inferred that Male participants are predominant with $62.1 \%$, and age group of 71-75 have the highest proportion of $31.7 \%$ while the age category with the least proportion was $81-85$ with $3.1 \%$. The marital status of the respondents showed that over half of them $(53 \%)$ are married and widowers have the least proportion of $6 \%$. Most of the respondents (38.4\%) have primary education and very few of them $(0.3 \%)$ have post graduate degrees. A fairly high proportion (43.9\%) of the respondents is self- employed while $5.8 \%$ of them have varying undetermined occupations. More than half of the respondents $(54.6 \%)$ have Islam as their religion, 39.6\% are Christians while only $5.8 \%$ have other religions they are practicing.

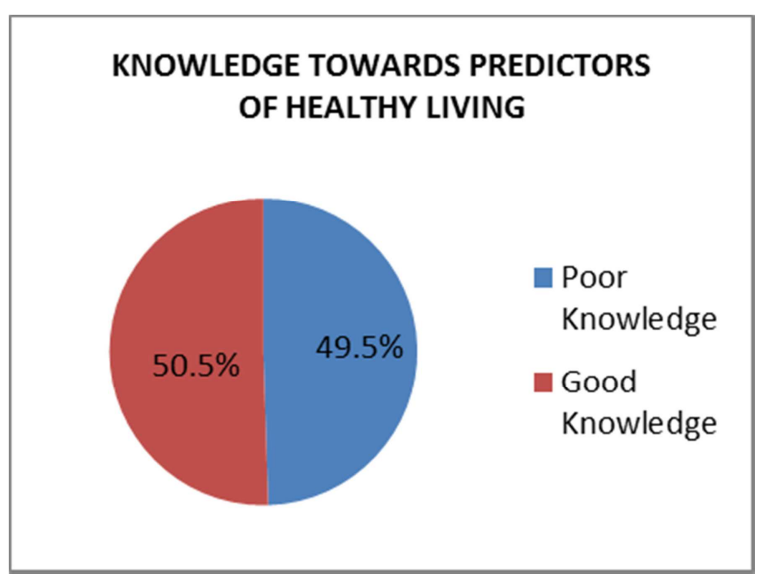

Figure 2. Knowledge distribution of respondents. 


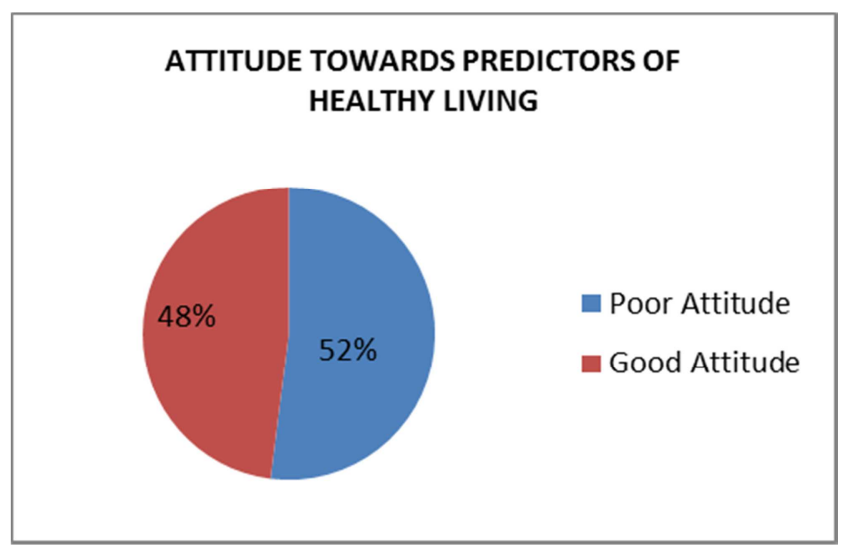

Figure 3. Attitude distribution of respondents.

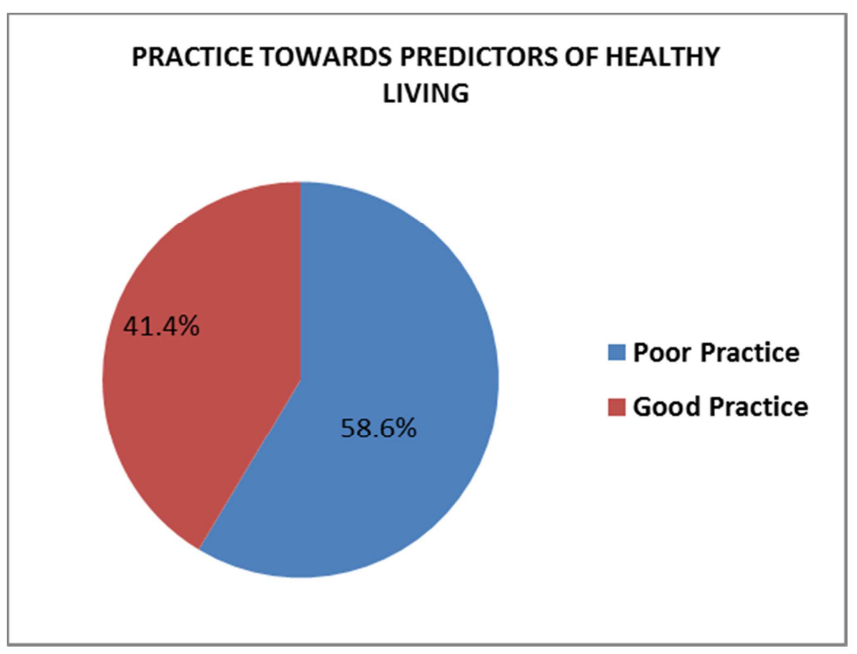

Figure 4. Practice distribution of respondents.

In figure 2 , slightly above half $(50.5 \%)$ of the respondents have good knowledge while $49.5 \%$ have poor knowledge towards predictors of healthy living. In figure 3 , over half (52\%) of the respondents have poor attitude and $48 \%$ of them have good attitude towards predictors of healthy living. Figure 4 reveals that almost two-third $(58.6 \%)$ of the respondents have poor practice while $41.4 \%$ of them have good practice towards predictors of healthy living.

Table 2. Knowledge association with socio-demographic variables.

\begin{tabular}{llll}
\hline Socio-Economic Variables & $\chi^{2}$ value & df & Sig. \\
\hline Age & 10.204 & 5 & 0.070 \\
Marital Status & 18.523 & 4 & $0.001^{* *}$ \\
Level of education & 4.071 & 4 & 0.396 \\
Employment status & 3.779 & 4 & 0.437 \\
Religion & $4.292^{\mathrm{a}}$ & 2 & 0.117 \\
\hline
\end{tabular}

** Significant at 0.05 alpha level

In table 2 above, marital status was found to have statistical significant association with the knowledge of the respondents towards predictors of healthy living $(\mathrm{P}<0.05)$, while age, level of education, employment status and religion have no statistical significant association with the respondents' knowledgee towards the predictors of healthy living $(\mathrm{P}>0.05)$.
Table 3. Attitude association with socio-demographic variables.

\begin{tabular}{llll}
\hline Socio-Economic Variables & $\chi^{2}$ & df & Sig. \\
\hline Age & $4.512^{\mathrm{a}}$ & 5 & 0.478 \\
Marital Status & $6.655^{\mathrm{a}}$ & 4 & 0.155 \\
Level of education & $15.200^{\mathrm{a}}$ & 4 & $0.004^{* *}$ \\
Employment status & $2.045^{\mathrm{a}}$ & 4 & 0.728 \\
Religion & $7.141^{\mathrm{a}}$ & 2 & $0.028^{* *}$ \\
\hline
\end{tabular}

** Significant at 0.05 alpha level

Table 3 above reveals that level of education and religion have statistical significant association with the attitude of the respondents towards the predictors of healthy living $(\mathrm{P}<0.05)$. Age, marital status and employment status have no statistical significant association with the attitude of the respondents towards predictors of healthy living $(\mathrm{P}>0.05)$.

Table 4. Practice association with socio-demographic variables.

\begin{tabular}{llll}
\hline Socio-Economic Variables & $\chi^{2}$ & Df & Sig. \\
\hline Age & $8.921^{\mathrm{a}}$ & 5 & 0.112 \\
Marital Status & $6.441^{\mathrm{a}}$ & 4 & 0.169 \\
Level of education & $10.880^{\mathrm{a}}$ & 4 & $0.028^{* *}$ \\
Employment status & $4.014^{\mathrm{a}}$ & 4 & 0.404 \\
Religion & $11.708^{\mathrm{a}}$ & 2 & $0.003^{* *}$ \\
\hline
\end{tabular}

** Significant at 0.05 alpha level

In table 4 above, level of education and religion were found to have statistical significant association with the practice of the respondents towards predictors of healthy living $(\mathrm{P}<0.05)$, while age, marital status and employment status have no statistical significant association with the practice of the respondents towards the predictors of healthy living $(\mathrm{P}>0.05)$.

\section{Discussion}

This study aimed at determining the level of knowledge, attitude and practice of the geriatrics towards the predictors of healthy living. It is of good note to have found respondents with around average $(50.5 \%)$ having good knowledge towards the predictor of healthy living, and this agrees with the work of Judy T. Zerzan et.al [5], that average number of geriatrics has been an "early adopter" of collaborative care models and interdisciplinary research and teaching related to healthy living. These skills and connections will prove useful in promoting this important agenda during a challenging time for health policy advocacy. This might have contributed to having adequate understanding of certain factors that they know could cumulatively assist individual to live healthily in the process of aging and with a long term effects on their health. Majority of the respondents are married (53.0\%) as supported by Nelson Chow and Xue Bai [6] that, marital status has been found in a number of studies to exert an influence on the health and mortality rate of older adults and there is an indication that, the elderly people living in rural areas, married, members of extended families, with less chronic illnesses, better neighborhood relationships, and showing greater interests in daily activities are more likely to 
be clustered into the group with a positive image of ageing and marital status were significant predictors of a negative/positive image.

Also in this study, the respondent with primary education have a higher proportion of 121 (38.4\%) though, this does not agree with the study of Nelson Chow [6] which stated that, one possible explanation for Chinese elderly people who often negatively perceived as "outdating in their knowledge and skills," "can't catch up with the times," "stubborn and useless," and, hence, in fighting back, they want to project a positive image of themselves, instead of being negatively stereotyped. Therefore to rectify this, it is suggested that public education about ageing must be mounted and programs must reflect both the positive and negative aspects of the process; only in this way, the understanding of the elderly will be enhanced about successful ageing.

Most of the elderly in this study were discovered to be self-employed (43.9\%), and the socioeconomic status were measured which refers to their current employment status, whether retired, still employed, or doing something else. This is to ascertain whether this characteristic, is significantly associated with the predictor of healthy living, and if it will be statistically significant in a multivariate context. Unger JB [7] on the other hand agreed to the fact that, the older adults with higher income may be more able to remain integrated within a social network, because of their ability to afford diversified activities and transportation that enhances their knowledge, attitude and practice. Most of the respondents are of Islamic faith (54.6\%) though, it was argue by Monika Ardelt [8] that, although religiosity tends to help older people to cope with physical and social losses, not all studies find a significant association between religious involvement and well-being in old age. It might be that primarily the intrinsic rather than the extrinsic aspect of religiosity is responsible for the positive effect of religiosity on well-being.

Furthermore, she used a sample of 103 community dwelling older adults $(58+)$, multivariate regression analyses showed that purpose in life rather than extrinsic or intrinsic religious orientation was positively related to elders' subjective well-being and negatively associated with fear of death and death avoidance. Moreover, extrinsic religious orientation had a positive effect on fear of death and death avoidance. Intrinsic religious orientation was positively related to approach acceptance of death. Frequency of shared spiritual activities and religious affiliation were unrelated to subjective well-being but positively related to death avoidance. M.-L. Chong [9] gave another side of the coin to religion that, the effect for Chinese older adults may be cultural indoctrination with family-oriented filial piety values.

Knowledge towards predictors of healthy living

Remarkably, out of $100 \%$ (319) respondents, $50.5 \%$ have good knowledge; while $49.5 \%$ have poor knowledge towards predictors of healthy living. This implies that almost half of the respondents have poor knowledge of healthy living while
$50.5 \%$ have good knowledge. In the same vein, the level of education was discovered to be statistically significant in association with the knowledge of the respondents towards predictors of healthy living $(\mathrm{P}<0.05)$. This implies that level of education may be responsible for the varying degrees of the respondents' knowledge towards the predictors of healthy living. It is proven that the level of education of the respondent helps good healthy lifestyle and will provide quality of life in aging healthily. The knowledge domain of the questionnaire probed their understanding of life style and that includes the following proper nutrition, regular physical activity, not smoking, prevention of alcoholic consumption, regular periodic checkups, management of stress, participation in social activities and being with family member. This finding was supported by Habibi Sola A. et.al [1]) that, every community needs to consider unique lifestyle techniques and utilize health instructions in order to have a healthy and longer life by enhancing healthy behaviors and modification of lifestyle which can greatly reduce the burden of diseases. Statistics on the main causes of death indicate that $53 \%$ of the causes are related to lifestyle and health behaviors. Applying prevention approaches and suitable efforts to postpone these conditions in the elderly population seems to be important through adequate knowledge which should cut across all age groups and especially from adolescents.

\section{Attitude towards predictors of healthy living}

Observing the attitude amongst the geriatrics in this study with the percentage distribution of their attitude towards predictor of healthy living raises a great concern. A greater proportion of the respondents $(52 \%)$ have poor attitude towards predictors of healthy living while less than half $(48 \%)$ have good attitude. This domain proves Bandura's argument that self-efficacy is one of the most important prerequisites of behavior. Prior research indicates that individuals with low self-efficacy who are not confident in their ability to perform a particular behavior tend to either not try to perform the behavior in question, or to give up easily when facing adversity [2]. However, this concern was substantiated by Marion E T McMurdo [11] study that, this negative tenor has been fueled partly by a misunderstanding about health in old age. Certainly older people in general have poorer health than younger people, and this is due partly to the higher rates of disease in old age. The incidence of heart disease, for example, increases with age, but this does not mean that ageing itself is a cause of heart disease. Nor does it mean that heart disease is inevitable in old age. The crucial distinction between the effects of age alone and the effects of disease do need to be reinforced in the minds of both the public and health professionals. Finally laying to rest the pervasive misconception that all the ills of old age are "just your age" would represent a major breakthrough for health care of older people. M.-L. Chong [9] study also shows that in Hong Kong Chinese people views about "positive aging," also suggested that having a positive life attitude, good health, and active engagement in activities important elements of positive ageing. 


\section{Practice towards predictors of healthy living}

It was discovered in the present study that, a greater proportion of the respondents $(58.6 \%)$ have poor practice towards predictors of healthy living while less than half $(41.4 \%)$ have good practice. Ford et al. (2008) reported, among older women, current health, and health related behaviors are stronger forecasters than social factors of comparatively early mortality. Accepting a healthier lifestyle, by doing more exercise and not smoking, is advantageous even in old age. However, elder psychological obstacle, lack of knowledge as an interpersonal and structural obstacle have all made it difficult for them to take part in healthy lifestyles. Consequently, besides the promotion of adhering healthy lifestyle by elder to stay healthy, more attention should also be paid to their internal and external difficulties in addition to improvement of the situation through facilities and arrangement of activities. Lack of healthy life style, is a reason to increase mortality and seniors with a healthier lifestyle, can experience healthy ageing and improve their quality of life. Therefore, assess the elderly life style in order to prevent disease and improve their quality of life is very important. In order to decrease barriers in adopting healthy lifestyle in the elderly, it needs to identify the exact difficulties to determine factors influencing them. According to a related study in Iran [12], that was conducted in suburban dwellers of Tehran city as capital of Iran. The older suburban dwellers are also likely to face various chronic physical and mental health problems based on some health indicators. Limited access to health care might help explain the overall poorer health of suburban residents who need more health-care services, but often have the fewest options and availability.

Furthermore, RP Thakur et al [13] proved the poor practice of a greater proportion of $58.6 \%$ among the geriatrics towards predictors of healthy living while less than half $(41.4 \%)$ having good practice may be due to rapid urbanization leading to more elderly people being left behind to fend for themselves in rural areas when the young migrate to the city in search of greener pastures and higher mean age of the rural elderly as brought out in the present study.

In this discussion it is worthy of note that, the higher illiteracy or the level of education with a higher mean age of the elderly add to the challenge of geriatric health issues in this group, as education has a positive impact on overall health. Similarly, the higher rate of religious belief amongst Nigerian is one of the findings of the present study also, and it has potential to adversely affect the health of elderly as religion is heavily dependent upon, for emotional and social support. An appreciable number not employed or drawing pension, thus not being economically independent, increases the burden of dependency.

\section{Conclusion}

Findings in this study suggest that there are variations in knowledge, attitude and practice of geriatrics towards predictor of healthy living. Also, marital status had great impact in achieving the desired and needed lifestyle as it was found to be associated with their knowledge of the subject matter. Hence, it seems in our society, family and social support play essential roles in achieving healthier lifestyle. Furthermore, most of the elderly had good knowledge but there are factors that prevent knowledge from becoming the integral part of their attitude. The effect of practice emanates from adequate health policies, with a consequential increase in knowledge. Therefore, the acquired knowledge may be effectively translated to attitude and practice with the advent of proper and increase in education during the youth and middle age of the elderly, also with adequate support by the families, community and the government. This research is carried out at the tertiary institution in Abuja to ascertain the degree of knowledge, attitude and practice of predictors of healthy living amongst the geriatrics to serve as a synergy to the Nigerian populace and other parts of the world to enable primary level prevention in public health, as related to geriatric health.

\section{Recommendations}

With respect to the findings of this study, the following recommendations were suggested;

(a) Legislating enabling laws by government, ensuring that the elderly are placed on monthly stipend and health insurance scheme.

(b) Information, education, and communication (health promotion) on social media on the care of the elderly.

(c) Community health workers, public health educators and social workers should plan appropriate technique to modify the attitude and practice during the health education and information.

(d) Providing proper education and training courses for health team especially nurses and associated staff involved to improve their knowledge and to take their role in educating the care giver on the care of the elderly.

(e) Future research should be directed to conducting both urban and rural community to provide national data with large number.

(f) Building an ideal hospice for the elderly with enough trained health care workers.

(g) Establishing geriatric training courses in the tertiary schools across the country.

\section{References}

[1] Margie E. Lachman, et al (2002), (2018) Change in Cognitive Performance from Midlife into Old Age.

[2] Bandura (1977, 1986), \& D. H. Schunk, Self-efficacy defined, International Encyclopedia of the Social \& Behavioral https://www.sciencedirect.com/topics/neuroscience/selfefficacy

[3] Ajzen, (1985); Hartwick \& Barki, (1994), Theory of Planned Behavior (TPB) predicts an individual's intention to have more resources and confidence http://www.mnsu.edu/its/academic/isalt_tpb.pdf 
[4] Rosenstock, Strecher, and Becker's (1988) - Health Belief Model - from Theory to Practice.

[5] Judy T. Zerzan et. al (2014) - Advancing Geriatrics Research, Education, and Practice: Policy Challenges After the Great Recession.

[6] Nelson Chow and Xue Bai (2006). The Effects of Sociodemographic Characteristics on Chinese Elders' Perception of the Image of Ageing then develop a positive attitude toward it, and after passing through these stages, engage in the behavior" International journal for numerical methods in engineering http://scholar.google.com

[7] Unger JB, McAvay G, Bruce ML, Berkman L, Seeman T (1999) Variation in the impact of social network characteristics on physical functioning in elderly persons: MacArthur Studies of Successful Aging. J Gerontol B Psychol Sci Soc Sci;54:S245-S251.

[8] Monika Ardelt (2006), The role of religion for hospice patients and relatively healthy older adults. Research on Aging Volume 28 Number 2 March 2006 184-215. Sage Publications 10.1177/0164027505284165

http://roa.sagepub.com hosted at http://online.sagepub.com
[9] M.-L. Chong, S.-H. Ng, J. Woo, and A. Y.-H. Kwan (2006) "Positive ageing: the views of middle-aged and older adults in Hong Kong," Ageing and Society, vol. 26, no. 2, pp. 243-265. View at Publisher View at Google Scholar.

[10] Habibi Sola A, Nikpor S, Rezayi M, Haghani H.(2007) Relationship between health promoting behaviors with the activities of daily living and activities of daily living with tools in elderly of Tehran. Iranian Journal of Aging. A healthy old age: realistic or futile goal?

[11] Marion E T McMurdo (2002) World Health Organization. Active ageing: A policy framework.

[12] Flood (2006) theory Ji, Link, and McCa, A Foucauldian Analysis of Old Age and the Power of Social Welfare https. https://www.researchgate.net/publication/12031717.

[13] RP Thakur, A Banerjee, 1 and VB Nikumb2 (2013) - Health Problems Among the Elderly: A Cross-Sectional Study World Health Organization Collaborative Programme supported by the Government of India. Multicentric study to establish epidemiological data on health problems in elderly. 